\title{
Increasing the degree of biological full-value of the litter with the use of black soldier fly (Hermetia Illucens) larvae
}

\author{
D.S. Bryukhanov*, Yu.V. Matrosova, and O.A. Vlasova \\ FSBEI HE South Ural SAU, Troitsk, Russia
}

\begin{abstract}
The development of the livestock and poultry industry in the Chelyabinsk region is increasing every year, in this regard, there is a problem of disposal of animals and poultry waste products. The development of a method for increasing the degree of biological full-value of the processing waste products of monogastric animals and birds using Hermetia illucens larvae, which will further make it possible to solve the problem of environmental pollution and obtain an alternative feed protein. Studies have been conducted to obtain a substrate using bacteria - Bacillus subtilis. The chemical composition of biohumus was determined. The composition of the biomass of Hermetia illucens larvae grown on a substrate enriched with a probiotic preparation, namely the content of crude protein and amino acids, was determined.
\end{abstract}

\section{Introduction}

At present, the global environmental crisis affect the humanity and causes great concern that due to the changes that have occurred in it, the habitat will be unsuitable for the life of the future generation.

Environmental pollution creates serious problems and can arise both as a result of the impact of natural factors and as a result of anthropogenic factors, i.e. human activities associated with ordinary human economic activities, with the work of enterprises, transport, etc.

Collection, utilization and processing of organic industrial, household and agricultural waste is one of the modern global environmental problems that lead to environmental pollution (air, water, soil), which negatively affects human health and the planet as a whole $[5,8]$.

It is possible to save the environment from agricultural waste due to the use of Hermetia illucens larvae, which will increase the biological full-value of litter and manure [2].

The use of larvae in the processing of agricultural waste will reduce the content of harmful bacteria, the concentration of nitrogen by $62 \%$ and this is very important, since the excess amount of nitrogen from agricultural waste (manure and litter) is washed out by rains and gets into the soil and reservoirs, thereby polluting them, also when working through manure or litter by larvae, it allows to reduce its mass. [6, 7]

${ }^{*}$ Corresponding author: bryuhanovd@inbox.ru 

2].

In addition, having a high growth rate, the larva quickly accumulates protein and fat [1,

The object of our research is the Black soldier fly (Hermetia illucens), which is of great interest in scientific activity and practical use; the creation of optimal artificial conditions for studying the vital activity of the species when studying the biological cycle of insect development in laboratory conditions will ensure the fly breeding and will allow the development of a number of biotechnology areas.

The main habitat of the Black soldier fly is countries with a warm climate, including in the subtropics, but recently, fly breeding technologies have been gaining popularity in regions with cold climatic conditions. Due to the high nutritional value of larvae and highly efficient bioconversion of solid organic waste, this type of insect can be used in feeding farm animals, poultry and aquaculture $[3,6,9]$.

The purpose of our research is to study the increase in the degree of biological fullvalue of the poultry waste products using Hermetia illucens larvae.

Based on the purpose of the study, the following tasks were set:

1. to study the chemical composition of chicken manure, biohumus, larvae;

2. to develop options for enriching the litter, allowing to accelerate the processing of poultry waste products, to assess the growth and development of the Black soldier fly larva, to assess the transformation of organic waste into feed biomass;

3. to determine the optimal parameters of cultivation of Hermetia illucens larvae in artificially created laboratory conditions.

\section{Material and methods}

The research was funded by RFBR and Chelyabinsk Region, project number 20-416$740008 \backslash 20$ "Development of a method for increasing the degree of biological usefulness of the processing waste products of monogastric animals and birds using Hermetia illucens larvae" and conducted in the conditions of the Department of Animal Husbandry and Poultry Breeding of the Institute of Veterinary Medicine of the South Ural State Agrarian University.

The purpose and tasks of the research were carried out on specially prepared substrates (litter with the addition of a culture of a probiotic preparation, namely a strain of soil spore bacteria Bacillus subtilis).

Bacillus subtilis bacteria were used to reduce the content of harmful gases, reduce the decomposition time of manure, as well as to disinfect poultry droppings from pathogenic microorganisms.

The resulting substrate was placed in a dark place and stored for a day at a temperature of $22^{\circ} \mathrm{C}$. After the expiration of time, the control substrate (litter) and the experimental substrate (litter+ Bacillus subtilis) were brought to the optimal humidity set in a series of experiments earlier - $78 \%$. This humidity was constantly maintained to obtain a positive effect of growing larvae.

It should be noted that the optimal temperature for the development of larvae in the room is $27^{\circ} \mathrm{C}$, which was monitored daily during the experiment. Natural lighting was mainly used with additional lighting during laboratory work.

The larvae were cultured in plastic containers on tables, 3-day-old grown larvae were introduced on the surface of the substrate, at the rate of $150 \mathrm{~g}$ of larvae per $5 \mathrm{~kg}$ of substrate.

The analysis of litter, biohumus and larvae was carried out in an interdepartmental laboratory according to generally accepted methods. 


\section{Results and discussion}

Our method of poultry manure processing is that we get eggs from the breeding stock of flies of the genus Hermetia illucens, incubate these eggs and after receiving the larvae we grow them on a nutrient medium, then on 5-6 day we separate the larvae of the II-III age, populate the substrate (litter with a probiotic preparation) with these larvae, on 6-8 day we separate the larvae from the resulting zoohumus.

For larvae rearing, a doughy mixture based on cereals was used as a nutrient medium, the larvae grow and develop much faster than with other nutrient media. It is impossible to plant not grown larvae immediately in poultry manure, as our studies show, they lag behind in growth and development, the disadvantage is a low yield of larvae biomass.

In the studies, poultry manure from poultry farms in the Chelyabinsk region was used, in which its chemical composition was determined according to generally accepted methods (Table 1).

Table 1. Chemical composition of the litter, in natural humidity.

\begin{tabular}{|c|c|}
\hline Indicator & Result \\
\hline Dry matter, $\%$ & $25.32 \pm 1.21$ \\
\hline $\mathrm{N}, \%$ & $1.85 \pm 0.13$ \\
\hline $\mathrm{P}, \%$ & $1.0 \pm 0.25$ \\
\hline $\mathrm{Ca}, \%$ & $1.72 \pm 1.18$ \\
\hline $\mathrm{pH}$ & $8.0 \pm 0.58$ \\
\hline $\mathrm{Fe}, \mathrm{mg} / \mathrm{kg}$ & $234.75 \pm 7.35$ \\
\hline $\mathrm{Cu}, \mathrm{mg} / \mathrm{kg}$ & $21.0 \pm 9.26$ \\
\hline $\mathrm{Zn}, \mathrm{mg} / \mathrm{kg}$ & $238.6 \pm 4.25$ \\
\hline $\mathrm{Co}, \mathrm{mg} / \mathrm{kg}$ & $1.43 \pm 0.05$ \\
\hline
\end{tabular}

The level of dry matter in the studied litter was $25.32 \%$, nitrogen $-1.85 \%$, calcium and phosphorus -1.72 and $1.0 \%$, respectively. According to our research, we see a large content of iron (234.75), zinc (238.6), manganese (59.17) in the litter. To a lesser extent - copper (21.0), cobalt (1.43). These elements are in a water-soluble form, being released gradually during the mineralization of organic matter.

Duration of manure processing into biohumus is of great importance in the poultry waste disposal technology. Figure 1 clearly shows the data on the duration and bioconversion of substrates by Hermetia illucens larvae.

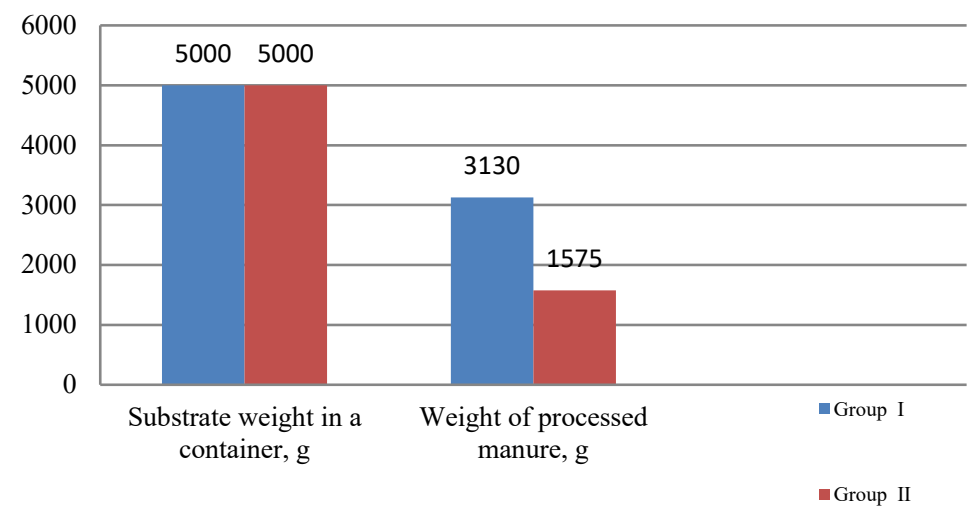

Fig. 1. Processing of manure. 


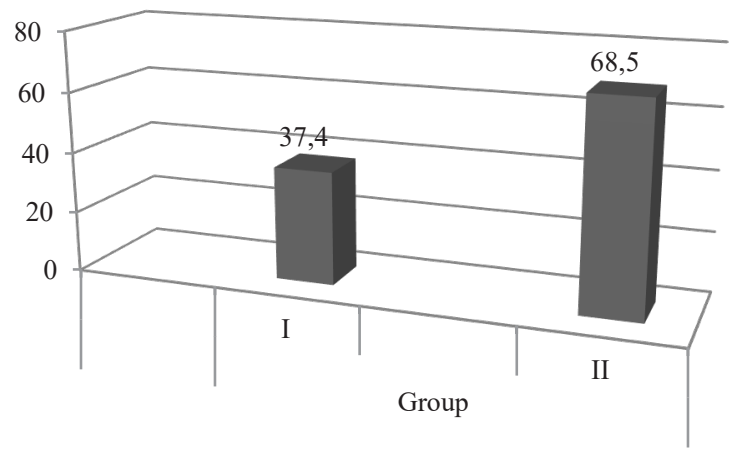

Fig. 2. Conversion, $\%$.

When Bacillus subtilis is added to the substrate, the period of manure processing by larvae is reduced by 2 days and is 6 days, while the mass of processed manure decreases by $1555 \mathrm{~g}$, and the larvae increase by $200 \mathrm{~g}$, compared with the control group I. The conversion of the substrate in the control group I was $37.4 \%$, in the group II with the addition of Bacillus subtilis to the manure $-68.5 \%$.

The conducted studies on determination of the chemical composition of biohumus in natural humidity are presented in Figures 3-6.

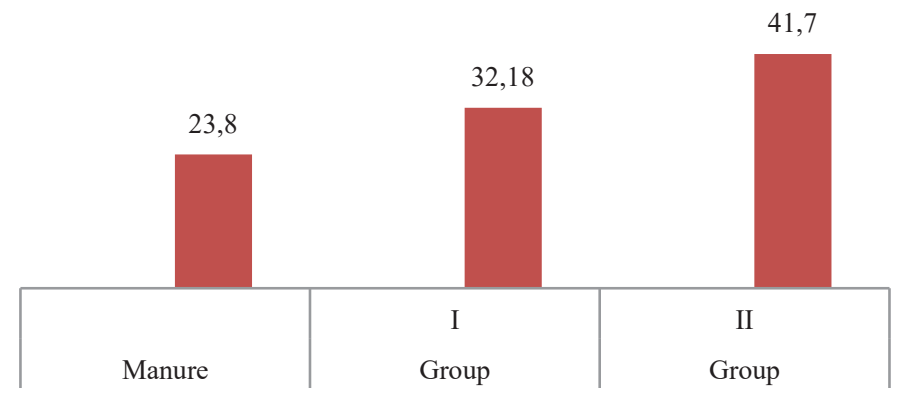

Fig. 3. Change in the level of dry matter in biohumus, $\%$.

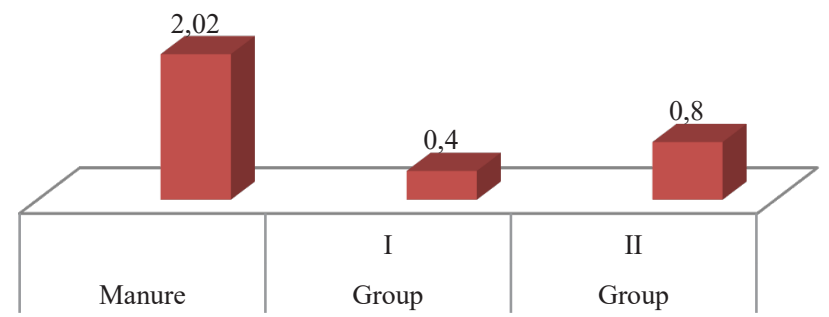

Fig. 4. Changes in the nitrogen level in biohumus, \%. 


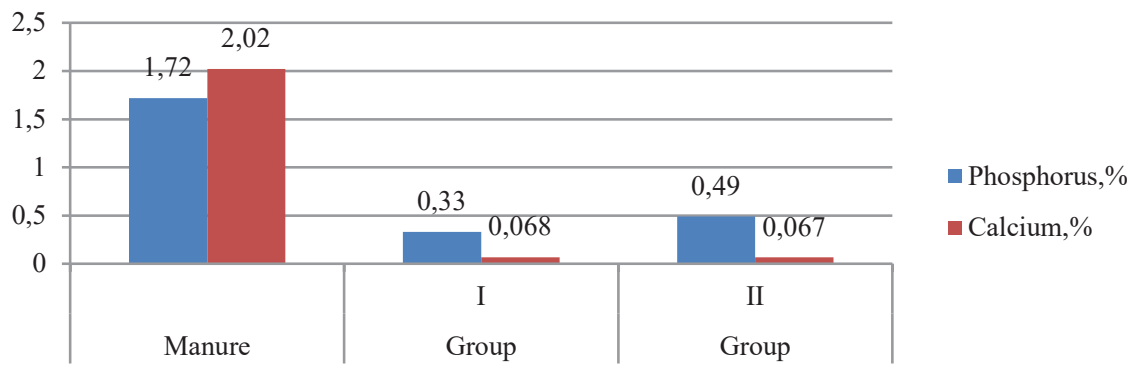

Fig. 5. Change in the level of trace elements in biohumus, $\%$.

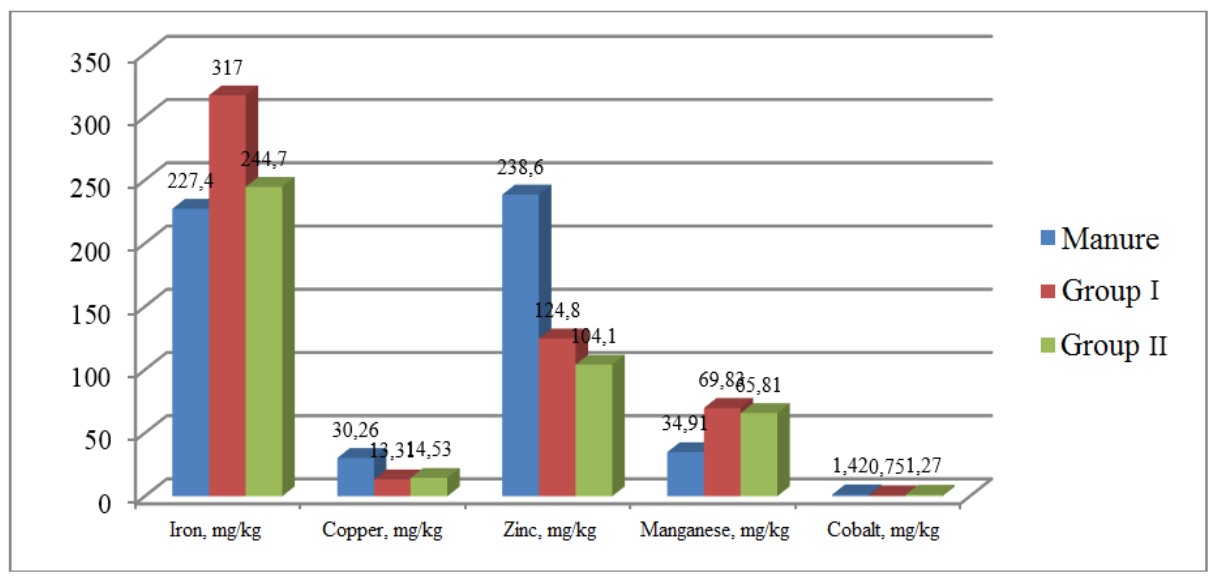

Fig. 6. Change in the level of trace elements in biohumus, $\mathrm{mg} / \mathrm{kg}$.

In the studied samples, an increase in dry matter occurred in relation to the initial indicators, so the level of dry matter was $32.18-41.7 \%$. Nitrogen in biohumus is reduced and is in the range of $0.4-0.8 \%$. A similar picture is noted for the content of macronutrients in biohumus and is $0.067-0.069 \mathrm{mg} / \mathrm{kg}$ for calcium, $0.33-0.49 \mathrm{mg} / \mathrm{kg}$ for phosphorus. The level of iron and manganese in biohumus increases and amounts to $244.7-317 \mathrm{mg} / \mathrm{kg}$ and 65.81-69.83 mg/kg, respectively, while the content of copper, cobalt and zinc decreases.

Hermetia illucens larvae are an economic way of converting the litter nutrients into a full-value biological source of proteins, lipids and chitin, as well as obtaining biohumus.

Comparing the two groups by the chemical composition of biohumus, from Table 2 we see that the content of dry matter, nitrogen, phosphorus, copper, and cobalt is higher in the second group. The calcium content is almost the same in the groups. The first group surpasses the second group in terms of the content of iron, zinc and manganese.

Table 2. Chemical composition of larvae in natural humidity

\begin{tabular}{|l|c|c|}
\hline \multirow{2}{*}{ Indicator } & \multicolumn{2}{|c|}{ Group } \\
\cline { 2 - 3 } & I & II \\
\hline Dry matter, \% & $26.88 \pm 3.48$ & $33.07 \pm 2.06$ \\
\hline Crude protein, \% & $11.98 \pm 1.01$ & $15.11 \pm 1.48$ \\
\hline $\mathrm{P}, \%$ & $0.25 \pm 0.01$ & $0.28 \pm 0.015$ \\
\hline $\mathrm{Ca}, \%$ & $0.85 \pm 0.24$ & $0.86 \pm 0.13$ \\
\hline $\mathrm{Fe}, \mathrm{mg} / \mathrm{kg}$ & $197.5 \pm 56.5$ & $261.7 \pm 94.1$ \\
\hline $\mathrm{Cu}, \mathrm{mg} / \mathrm{kg}$ & $5.94 \pm 0.06$ & $7.23 \pm 0.68$ \\
\hline $\mathrm{Zn}, \mathrm{mg} / \mathrm{kg}$ & $88.46 \pm 15.84$ & $110.85 \pm 17.05$ \\
\hline $\mathrm{Co}, \mathrm{mg} / \mathrm{kg}$ & $0.22 \pm 0.035$ & $0.45 \pm 0.09$ \\
\hline
\end{tabular}




\begin{tabular}{|l|c|c|}
\hline $\mathrm{Mn}, \mathrm{mg} / \mathrm{kg}$ & $62.42 \pm 0.005$ & $78.69 \pm 6.04$ \\
\hline Arginine, \% & $0.51 \pm 0.06$ & $0.58 \pm 0.03$ \\
\hline Lysine, \% & $0.35 \pm 0.03$ & $0.52 \pm 0.01$ \\
\hline Tyrosine, \% & $0.27 \pm 0.02$ & $0.29 \pm 0.01$ \\
\hline Phenylalanine, \% & $0.19 \pm 0.01$ & $0.39 \pm 0.04$ \\
\hline Histidine, \% & $0.12 \pm 0.02$ & $0.11 \pm 0.01$ \\
\hline Leucine+isoleucine, \% & $0.73 \pm 0.08$ & $0.85 \pm 0.06$ \\
\hline Methionine, \% & $0.08 \pm 0.01$ & $0.08 \pm 0.01$ \\
\hline Valine, \% & $0.26 \pm 0.015$ & $0.46 \pm 0.02$ \\
\hline Proline, \% & $0.31 \pm 0.01$ & $0.33 \pm 0.02$ \\
\hline Threonine, \% & $0.26 \pm 0.06$ & $0.26 \pm 0.04$ \\
\hline Serine, \% & $0.32 \pm 0.11$ & $0.34 \pm 0.02$ \\
\hline Alanine, \% & $0.36 \pm 0.04$ & $0.59 \pm 0.02$ \\
\hline Glycine, \% & $0.29 \pm 0.01$ & $0.35 \pm 0.01$ \\
\hline
\end{tabular}

The protein content in the larvae was at the level of $11.98-15.11 \%$. On the substrate with the addition of Bacillus subtilis in the larval biomass, the level of crude protein was $23 \%$ higher relative to the control. The levels of calcium and phosphorus were almost the same and amounted to $0.85-0.86$ and $0.25-0.28 \%$, respectively.

The trend of increasing iron, zinc, cobalt, and manganese in larvae obtained on a substrate with the addition of Bacillus subtilis is observed.

After analyzing the data, we can say that the larvae grown on an enriched substrate (Bacillus subtilis) exceed the larvae of the control group in terms of the content of lysine, valine, phenylalanine, arginine, proline, serine, alanine. The amino acid composition of the protein is characteristic of animal protein. In this way, the data obtained by us allows to conclude that the larval biomass obtained by us has improved indicators of mineral and amino acid composition.

\section{Conclusions and discussions}

Therefore, we can reduce the time of transformation of poultry manure into products useful for humans, obtain an effective fertilizer, and also use the larvae biomass as a feed additive.

Processing of litter with the help of larvae of the Black soldier fly (Hermetia Illucens) is environmentally friendly, since instead of methane, only a certain amount of carbon dioxide is released into the atmosphere. Methane is an air pollutant that causes a global greenhouse effect [8].

We propose to use the results of the conducted research in agriculture when processing the poultry waste products, as well as to use larval biomass in feeding animals and birds.

Considering that currently the ecological problem is in the first place, and agricultural enterprises, especially industrial farms and complexes, pollute the ecosystem as much as possible, it is expected that the results of our work will find their application in agriculture of the Chelyabinsk region.

\section{Acknowledgments}

The research was funded by RFBR and Chelyabinsk Region, project number 20-41000001» 


\section{References}

1. C. Jucker, D. Erba, MG Leonardi, D. Lupi, S. Savoldelli, Environ Entomol 46, 14151423 (2017)

2. D.G. Oonincx, J. van Itterbeeck, M.J. Heetkamp, H. van den Brand, J.J. van Loon, A. van Huis, Plos One 5 (12) e14445, (2010) https://doi.org/10.1371/journal.pone. 0014445.

3. A.M. Antonov, E. Lutovinovas, G.A. Ivanov, N.O. Pastukhova, Principles of ecology 3, 4-19 (2017)

4. A.K. Bochkarev, D.S. Bryukhanov, S.M. Ermolov, The influence of temperature and humidity regime on the growth and development of larvae of Black soldier flies, Actual issues of biotechnology and veterinary medicine: theory and practice, mater. of national scientific conference of the Institute of Veterinary Medicine (Troitsk, 2018) 17-21 (Chelyabinsk: FSBEI HE South-Ural SAU, 2018)

5. M.A. Bochkareva, A.K. Bochkarev, O.A. Matrosova, Obtaining eggs of the black soldier fly in the conditions of the Department of Animal Husbandry and Poultry Breeding, Ideas of young scientists-agro-industrial complex: zootechny, veterinary medicine and technology of processing agricultural products, mater. of student scientific conference of the Institute of Veterinary Medicine (Troitsk, 2019) 36-39 (Chelyabinsk: FSBEI HE South-Ural SAU, 2019)

6. O.A. Vlasova, D.S. Bryukhanov, A.K. Bochkarev, The biological cycle of the Black soldier fly in the conditions of the Department of Animal Husbandry and Poultry Breeding of the Institute of Veterinary Medicine of the SUrSAU, Actual issues of biotechnology and veterinary medicine: theory and practice, mater. of national scientific conference of the Institute of Veterinary Medicine (Troitsk, 2018) 35-40 (Chelyabinsk: FSBEI HE South-UralSAU, 2018)

7. V.F. Protasov, A.V. Molchanov, Ecology, health and nature management in Russia, 528 (M.: Publishing house of Finance and Statistics, 1995)

8. D.N. Serebryansky, Processing of food and agricultural waste by black soldier fly larvae. Obtaining feed protein, fertilizers and chitin, (2015) https://agrobook.ru/blog/user/sdn15/pererabotka-pishchevyh-i-selskohozyaystvennyhothodov-lichinkami-chernoy-lvinki

9. N.A. Ushakova, R.V. Nekrasov, Prospects for the use of insects in feeding farm animals. Biotechnology: the state and prospects of development, Materials of the VIII Moscow International Congress, CJSC "Expo-Biohim-technologies", RSTU n.a. D.I. Mendeleev (Moscow, March 17-20, 2015), 147-149 (2015) 